\title{
Association of the interleukin 1 receptor antagonist gene with ulcerative colitis in Northern European Caucasians
}

\author{
M J Carter, F S di Giovine, S Jones, J Mee, N J Camp, A J Lobo, G W Duff
}

\begin{abstract}
Background and aims-An association between the allele 2 of the interleukin 1 receptor antagonist gene variable number tandem repeats polymorphism in intron 2 and ulcerative colitis was first reported in 1994. Subsequent studies in Caucasian Northern European patients have not confirmed this, although trends towards an association were observed. The lack of statistical significance could reflect inadequate power. In this study the association was reassessed in a large independent set of well characterised Caucasian patients and a meta-analysis of reported patient series was performed.
\end{abstract}

Patients and methods-A total of 320 patients with endoscopically and histologically confirmed ulcerative colitis (124 pancolitis, 196 left sided and distal disease) and 827 ethnically matched controls were genotyped at polymorphic sites in the interleukin 1 receptor antagonist gene. Carriage rates were compared using $\chi^{2}$ statistics. A meta-analysis of this and seven previous studies in North European Caucasian patients was performed using the Mantel-Haenszel $\chi^{2}$ test.

Results-Patients had a significantly increased carriage rate of allele 2 compared with controls $(52 \% v 45 \%$; odds ratio 1.3 (95\% confidence interval (CI) 1.01-1.7); $\mathrm{p}=0.04)$. The allele 2 carriage rate was highest in extensive colitis (carriage rate $56 \%$; odds ratio 1.5 (95\% CI $1.1-2.3)$ $\mathbf{p}=0.02$ ) and in individuals who had undergone colectomy (carriage rate 55\%; odds ratio 1.5 (95\% CI $0.95-2.4) ; \mathrm{p}=0.08)$. Meta-analysis of all eight studies showed a significant association between carriage of allele 2 and ulcerative colitis (odds ratio 1.23 (95\% CI 1.04-1.45); $p=0.01$ ).

Conclusions-The association of the interleukin 1 receptor antagonist gene polymorphism with ulcerative colitis is confirmed. The association is minor and confers only a small risk to an individual but will contribute a high attributable risk in a population due to the high allelic frequency. Accurate phenotypic characterisation defines more homogeneous subsets of patients, such as those with extensive disease, in whom the association is greater.

(Gut 2001;48:461-467)

Keywords: ulcerative colitis; cytokine gene polymorphisms; interleukin 1 receptor antagonist; interleukin 1; inflammatory bowel disease; genetics
The causes of the common forms of idiopathic inflammatory bowel disease (IBD), ulcerative colitis (UC) and Crohn's disease (CD), remain unknown. The higher concordance rates in monozygotic compared with dizygotic twins $(26 \%$ v $2 \%),{ }^{1}$ familial clustering of disease, ${ }^{2}$ and ethnic variability of disease incidence suggests that genetic factors play a role. Segregational analysis indicates that a simple mendelian model of inheritance is not applicable ${ }^{3}$ and both the epidemiological data and clinical variability in disease suggest that IBD is a heterogeneous group of related polygenic disorders with undetermined environmental factors contributing to pathogenesis and disease phenotype. ${ }^{4}$ This hypothesis has been further supported by the recent genome wide linkage studies in IBD which have identified multiple candidate loci with each accounting for only a small proportion of the overall genetic risk. ${ }^{56}$

Cytokines have been implicated in the pathogenesis of many chronic inflammatory diseases where genetic factors have been shown to have a role in determining disease susceptibility and severity. Furthermore, cytokines have a substantial regulatory and effector role in the mucosal immune and inflammatory response in IBD. ${ }^{7}$ The interleukin 1 cytokine family has been an area of considerable interest. ${ }^{8}$ Interleukin 1 (IL-1) alpha and beta are major proinflammatory cytokines involved early in the inflammatory cascade. The interleukin 1 receptor antagonist (IL-1ra) is the natural inhibitor of these IL-1 agonists and acts by competitively binding to IL-1 receptors without eliciting signal transduction. ${ }^{9}$ All three proteins are coded by genes in the IL- 1 gene cluster on the long arm of chromosome $2 .^{10}$

Enhanced production of IL-1 has been shown in the gut tissue of animal models of intestinal inflammation, ${ }^{11}{ }^{12}$ and in the colonic mucosa ${ }^{13}$ and by cell preparations isolated from the intestine of patients with IBD. ${ }^{14}$ Tissue levels correlate with disease activity but the IL-1 ra/IL-1 ratio shows the closest correlation with inflammation. ${ }^{15} 16$ Furthermore, rabbit immune complex colitis is attenuated by administration of $\mathrm{IL}-1 \mathrm{ra}^{17}$ and reduction of IL-1ra levels by either gene knockout in mice ${ }^{18}$

Abbreviations used in this paper: IL-1 ra, interleukin 1 receptor antagonist; IL-1, interleukin 1 ; IL-1RN, interleukin 1 receptor antagonist gene; VNTR, variable number of tandem repeats; PCR, polymerase chain reaction; SNP, single nucleotide polymorphism; IBD, inflammatory bowel disease; UC, ulcerative colitis; $\mathrm{CD}$, Crohn's disease; OR, odds ratio. 
or by antibody neutralisation in rabbits $^{19}$ increases the susceptibility to the induction of experimental colitis. An imbalance in the biologically important IL-1ra/IL-1 ratio may therefore contribute to the chronic inflammatory response in UC. Such biological observations suggest that the IL-1 gene locus is an appropriate candidate region for studying the genetic susceptibility to UC.

A variable number of tandem repeats (VNTR) polymorphism exists within intron 2 of the IL-1ra gene (IL-1RN).${ }^{20}$ Five alleles have been described but alleles 1 and 2 account for more than $95 \%$. Subsequently, a number of single nucleotide polymorphisms (SNPs) have been described in the IL-1RN..$^{21}$ Two such SNPs are a $\mathrm{T}$ to $\mathrm{C}$ base pair change at position +2018 in exon 2 (creating a $M s p I$ restriction site $^{21}$ ) and a $\mathrm{C}$ to $\mathrm{T}$ base pair change at position +2073 in intron 2 (disrupting a MwoI restriction site ${ }^{22}$ ). The rarer alleles of these 2 biallelic polymorphisms are completely associated with allele 2 of the intronic VNTR polymorphism. ${ }^{2122}$

An association between carriage of allele 2 of the intronic polymorphism and UC was first reported in $1994 .^{23}$ This was strongest in patients with total colitis. Subsequent investigations in Jewish and Hispanic populations have confirmed this association ${ }^{24}{ }^{25}$ but reports from studies on North European Caucasian populations have been conflicting. Of the five subsequent studies, ${ }^{26-30}$ none provided statistically significant evidence to confirm the genetic association although there was a trend towards an association in three. ${ }^{26-2730} \mathrm{~A}$ single study showed a statistically significant negative association between the allele and the disease. ${ }^{29} \mathrm{~A}$ seventh study using the MwoI SNP in intron 2 as a marker for the VNTR polymorphism also showed a non-significant trend towards association. ${ }^{31}$ However, all of these series lacked the power to exclude a false negative result. Furthermore, the diagnostic criteria used for patient selection were not uniformly clear which may have allowed inclusion of patients without UC such as those with indeterminate or Crohn's colitis.

Therefore, the aim of our study was to reassess the putative association between allele 2 of the intronic IL-1RN polymorphism and UC. Two approaches were used. Firstly, a large independent series of clinically well characterised, unrelated, white British Caucasian patients with UC were genotyped and their carriage rate of allele 2 compared with that of a large group of ethnically matched controls. Secondly, the results of this study and those of the seven previous published studies were combined in a meta-analysis.

\section{Methods}

PATIENTS AND CONTROLS

A total of 320 patients with UC were studied. Diagnosis and extent of disease were confirmed either by colonoscopy within the previous four years with histological examination of a colonic series of biopsies or by histological assessment of the colectomy specimen. Patients were included only if histological assessment was suggestive, highly suggestive, or diagnostic of UC according to the guidelines of the British Society of Gastroenterology. ${ }^{32}$ Individuals with the appearance of indeterminate chronic inflammatory bowel disease were excluded. Macroscopic and microscopic confirmation of contiguous inflammation extending for a variable distance from the rectum were necessary for inclusion. Patients with rectal sparing or focal inflammation were excluded. Where microscopic and macroscopic disease extent differed, the histological limit of inflammation was used to define disease extent. This was classified as either extensive or non-extensive depending on whether or not the inflammation extended beyond the splenic flexure. These patients represent approximately $30 \%$ of patients with UC attending our inflammatory bowel disease clinic. None of the patients studied was in the initial Sheffield study. ${ }^{23}$ Demographic data, including sex, age at diagnosis, extent of colitis, need for colectomy, and family history of UC and IBD are shown in table 1.

The study was approved by the South Sheffield Research Ethics Committee in 1994. All patients participated in the study after giving informed written consent.

A total of 827 control individuals were anonymous blood donors in the North Trent region and all were Caucasian Northern European individuals. All samples were collected in 1997 and were independent of the control population used in the study by Mansfield and colleagues. ${ }^{23}$ This control DNA was collected with full ethics approval in 1997 although individuals were anonymous and did not give consent.

GENOTYPING

Blood was obtained into ethlyenediaminetetraacetic acid tubes $(2 \times 10 \mathrm{ml})$ and stored frozen until extracted. DNA was extracted by a modification of the saltout technique ${ }^{33}$ and was stored at $4^{\circ} \mathrm{C}$.

The VNTR polymorphism was genotyped as described previously. ${ }^{23}$ Briefly, DNA was amplified using primers flanking the 86 base pair tandem repeat polymorphic region within intron 2 of IL-1RN (sense, 5'CTC.AGC.AAC.ACT.CCT.AT-3' and antisense, 5'-TCC.TGG.TCT.GCA.GGT.AA-3').

Table 1 Demographic characteristics of patients with ulcerative colitis (UC)

\begin{tabular}{ll}
\hline Total No & 320 \\
Sex $(M / F)$ & $160 / 160$ \\
Age at diagnosis (y) & \\
$\quad$ Range & $4-80$ \\
$\quad$ Median & 32 \\
$\quad$ Mean & 34.5 \\
Extent of UC (\%) & $124(39)$ \\
$\quad$ Extensive & $196(61)$ \\
$\quad$ Non-extensive & $80(25)$ \\
Surgery (\%) & $49(15)$ \\
Family history of IBD (\%) & $40(12.5)$ \\
Family history of UC (\%) & \\
\hline
\end{tabular}

Extensive ulcerative colitis is defined as disease where inflammation extends beyond the splenic flexure while nonextensive disease refers to disease where the inflammation is limited to the left colon and includes left sided colitis, proctosigmoiditis, and proctitis.

A family history is defined as the presence of disease in a first or second degree relative.

IBD, inflammatory bowel disease. 
Polymerase chain reaction (PCR) was performed with one cycle of one minute at $96^{\circ} \mathrm{C}$, 35 cycles of one minute at $94^{\circ} \mathrm{C}$, one minute at $60^{\circ} \mathrm{C}$, and one minute at $70^{\circ} \mathrm{C}$, followed by five minutes at $70^{\circ} \mathrm{C}$. PCR products were electrophoresed on a $2 \%$ agarose gel and visualised under ultraviolet light after staining with ethidium bromide.

The +2018 exon 2 SNP was genotyped as described previously. ${ }^{21}$ Briefly, a 154 base pair fragment encompassing the polymorphic site of the template DNA was amplified using a forward primer 5'-CTA.TCT.GAG.GAA. CAA.CCA.ACT.AGT.AGC-3' adjoining the polymorphic site and a reverse primer 5'TAG.GAC.ATT.GCA.CCT.AGG.GTT.TGT3'. The forward primer contains a single base mismatch two bases from the 3 ' end to engineer an $A l u \mathrm{I}$ restriction site in allele 1 (AG $\mathbf{A G T G}^{\mathrm{V}} \mathrm{C}$ ). Allele 2 itself completes a restriction site for MspI (AGC ${ }^{v}$ CGG). PCR was performed with one cycle of one minute at $96^{\circ} \mathrm{C}, 35$ cycles of one minute at $94^{\circ} \mathrm{C}$, one minute at $57^{\circ} \mathrm{C}$, and two minutes at $70^{\circ} \mathrm{C}$, followed by five minutes at $70^{\circ} \mathrm{C}$. Each PCR mixture was then divided into two aliquots and separately digested with $A l u \mathrm{I}$ or $M s p \mathrm{I}$. PCR products were size fractionated by $9 \%$ polyacrylamide gel electrophoresis and visualised under ultraviolet light after staining with ethidium bromide. The two enzymes cut the two alleles differently. AluI cuts the 154 base pair fragment to produce 126 and 28 base pair fragments in allele 1 while it does not digest allele 2 (154 base pairs). MspI digestion produces 125 and 29 base pair fragments in allele 2 but does not digest allele 1 (154 base pairs). Hence the two reactions (separated side by side on a gel) will give inverted patterns of digestion for homozygous individuals, and identical patterns in heterozygotes (fig 1).

Initially 269 patients and controls were genotyped for both of the above polymorphisms to confirm in a large group of individuals that allele 2 of the VNTR polymorphism and allele 2 of the exon 2 polymorphism are in $100 \%$ linkage disequilibrium. The results of this initial study are shown in table 2 and confirm that these two alleles are completely associated. Therefore, for this study we genotyped all patients and controls for the IL-1RN $(+2018)$ polymorphism as a marker of VNTR polymorphism.

META-ANALYSIS

A Medline search of the literature and review of gastroenterology conference abstracts since 1994 identified seven studies of IL-1RN polymorphisms in UC in white Northern European Caucasian populations..$^{23}$ 26-31 Only studies which examined UC patients as a whole were included. Those series which involved any degree of selection of patients, such as those that considered only surgical patients, ${ }^{25} 3435$ were excluded to ensure that the analysis reflected, as far as possible, overall disease susceptibility.

For the purposes of the meta-analysis the VNTR polymorphism is considered as collapsed into a biallelic system consisting of the

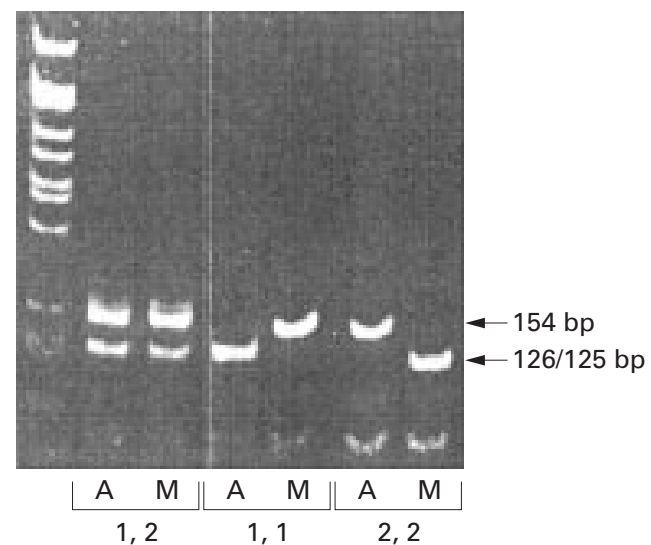

Figure 1 Interleukin 1 receptor antagonist gene $(I L-1 R N)+2018$ exon 2 single nucleotide polymorphism genotyping using restriction enzyme digestion of amplified polymerase chain reaction (PCR) products. Lane 1 contains a standard DNA ladder. Lanes 2-7 contain DNA from three individuals. Amplified PCR products from each individual were divided into two aliquots and separately digested with AluI or MspI. PCR products were size. fractionated by $9 \%$ polyacrylamide gel electrophoresis and visualised under ultraviolet light after staining with ethidium bromide. The two enzymes cut the two alleles differently. AluI cuts the 154 base pair fragment to produce 126 and 28 base pair fragments in allele 1 while it does not digest allele 2 (154 base pairs). MspI digestion produces 125 and 29 base pair fragments in allele 2 but does not digest allele 1 (154 base pairs). Hence the two reactions (separated side by side on a gel) will give inverted patterns of digestion for homozygous individuals (lanes $4 / 5$ and $6 / 7)$, and identical patterns in heterozygotes (lanes 2/3).

Table 2 Comparison of the exon $2(+2018)$ interleukin 1 receptor antagonist gene (IL-1RN) polymorphism and variable number of tandem repeats (VNTR) IL-1RN polymorphism genotypes in 269 individuals demonstrating complete concordance between the VNTR allele 2 and the rarer allele $(C)$ of the exon 2 polymorphism

\begin{tabular}{lrrrrrr}
\hline & \multicolumn{2}{c}{ VNTR } & & & \\
& 1,1 & 1,2 & 2,2 & 1,3 & 1,4 & 2,3 \\
\hline Exon 2 & & & & & & \\
$1,1(\mathrm{~T}, \mathrm{~T})$ & 124 & 0 & 0 & 3 & 1 & 0 \\
$1,2(\mathrm{~T}, \mathrm{C})$ & 0 & 113 & 0 & 0 & 0 & 3 \\
$2,2(\mathrm{C}, \mathrm{C})$ & 0 & 0 & 25 & 0 & 0 & 0 \\
\hline
\end{tabular}

disease associated allele 2 and all other alleles. This enables the results of this study and the single study using the MwoI intron 2 polymorphism to be appropriately combined with those studies in which the VNTR polymorphism itself was genotyped.

STATISTICAL METHODS

Carriage rates of allele 2 were compared between cases and controls from a $2 \times 2$ contingency table using the $\chi^{2}$ test for independence. Odds ratios were also calculated for the disease for carriage of allele 2. Observed allele frequencies have been quoted in table 3 for illustrative purposes but all analyses were performed based on genotypes rather than allele frequencies since the testing of alleles is invalid if population stratification exists. ${ }^{36}$ The meta-analysis was performed using the Mantel-Haenszel $\chi^{2}$ test $^{37}$ with validity evaluated by the method of Mantel and Fleiss. ${ }^{38}$ Woolf's method was used for calculating the combined odds ratio (OR) with 95\% confidence intervals (CI) and to perform a statistical test of heterogeneity. ${ }^{39}$ 
Table 3 Interleukin 1 receptor antagonist gene (IL-1RN) genotypes in controls, patients with ulcerative colitis, and in subgroups of patients with ulcerative colitis according to disease phenotype

\begin{tabular}{|c|c|c|c|c|c|c|}
\hline & \multicolumn{4}{|c|}{$I L-1 R N$ genotype } & \multirow{2}{*}{$\begin{array}{l}I L-1 R N^{\star} 2 \\
\text { carriage (\%) }\end{array}$} & \multirow[b]{2}{*}{$\begin{array}{l}I L-1 R N^{\star} 2 \\
\text { frequency (\%) }\end{array}$} \\
\hline & $n$ & 1,1 & 1,2 & 2,2 & & \\
\hline Controls & 827 & 456 & 317 & 54 & 44.9 & 25.7 \\
\hline Ulcerative colitis & 320 & 155 & 139 & 26 & 51.6 & 29.8 \\
\hline Extensive colitis & 124 & 55 & 58 & 11 & 55.6 & 32.2 \\
\hline Non-extensive colitis & 196 & 100 & 81 & 15 & 49.0 & 28.3 \\
\hline Colitis requiring colectomy & 80 & 36 & 37 & 7 & 55.0 & 31.9 \\
\hline
\end{tabular}

Extensive ulcerative colitis is defined as disease where inflammation extends beyond the splenic flexure while non-extensive disease refers to disease where the inflammation is limited to the left colon and includes left sided colitis, proctosigmoiditis, and proctitis.

To compare the current study with those performed previously by others, the power to detect an OR of 2.0 was calculated for each study (table 4). These power calculations assumed Hardy-Weinberg equilibrium, and used the control frequency for allele 2 specific for each study. Assuming an OR of 2.0, the alternative hypothesis disease allele frequency can be calculated, and hence power can be calculated using the normal approximation for testing proportions.

\section{Results}

IL-1RN GENOTYPES

Table 3 shows the IL-1RN genotypes, IL$1 \mathrm{RN}^{\star} 2$ carriage rate, and allele frequency for the controls, UC patients, and patient subgroups defined by extent of inflammation and surgery. These results give an allele 2 carriage rate of $52 \%$ in UC patients and $45 \%$ in healthy controls showing a significant association between carriage of allele 2 and UC (OR 1.3 (95\% CI 1.01-1.7); $\left.\mathrm{p}=0.04 ; \chi^{2}=4.16 ; 1 \mathrm{df}\right)$.

The association with allele 2 was most pronounced in patients with extensive disease, with a carriage rate of $56 \%$ (OR 1.5 (95\% CI $1.1-2.3) ; \mathrm{p}=0.02$ ) compared with $52 \%$ in all UC patients and $50 \%$ in patients with left sided colitis (OR 1.2 (95\% CI 0.9-1.6); p=0.3). When patients who have required a colectomy were analysed separately there was also a trend towards association with carriage of allele 2 $(55 \%$ v $45 \%$ in controls; OR 1.5 (95\% CI $0.95-2.4) ; \mathrm{p}=0.08)$.

META-ANALYSIS

Details of studies, including genotypes of the patients and controls, are given in table 4 . OR values for all identified studies of the IL-1RN
Study (reference)

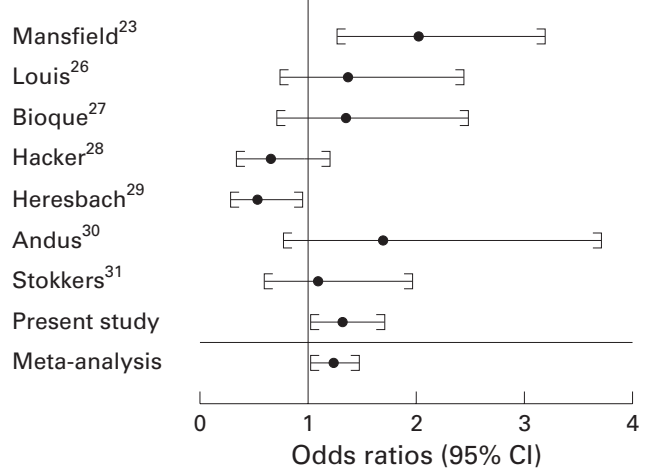

Figure 2 Graphic display of individual and summary odds ratios with $95 \%$ confidence intervals (CI) for the seven previously published studies of the interleukin 1 receptor antagonist gene (IL-1RN) polymorphism in ulcerative colitis, the present study, and the meta-analysis. Studies are shown as first author with the reference number.

polymorphism in UC are shown in fig 2 . Analysis of these results using the MantelHaenszel $\chi^{2}$ method showed an overall association between allele 2 carriage and UC $\left(p=0.01 ; \chi^{2}=6.0 ; 1 \mathrm{df}\right)$. This result was valid according to the Mantel and Fleiss method. Woolf's method calculated an odds ratio of 1.23 (95\% CI 1.04-1.45). However, the test for heterogeneity across studies was significant $\left(\chi^{2}=18.1 ; 7\right.$ df; $\left.p=0.01\right)$.

\section{Discussion}

This is the largest study to date assessing IL-1RN allelic carriage rates in UC. The results of the association study confirm that carriage of allele 2 is significantly associated with the disease. Although the IL-1RN association can only explain a small proportion of the overall genetic susceptibility to UC, this is in accordance with the currently accepted concept that the condition is a polygenic disorder with a potentially large number of genetic variants each contributing individually only a small genetic risk. In complex traits, although a genetic locus may confer only a small risk to the individual (compared with a monogenic disease) it may, however, have a high attributable risk in the population because of a high gene frequency. Attributable risk is the proportion of people affected with a disease due to a certain gene or genes. This may apply to the IL-1RN polymorphism. Detection of minor genes is much more difficult than identification of

Table 4 Interleukin 1 receptor antagonist gene (IL-1RN) genotypes of patients with ulcerative colitis (UC) and controls, odds ratios (OR), and power of association studies in Northern European Caucasian populations

\begin{tabular}{|c|c|c|c|c|c|c|c|c|c|c|}
\hline \multirow[b]{3}{*}{ Author } & \multirow[b]{3}{*}{ OR $(95 \% C I)$} & \multirow{3}{*}{$\begin{array}{l}U C \\
n\end{array}$} & \multirow{3}{*}{$\begin{array}{c}H C \\
n\end{array}$} & \multicolumn{7}{|c|}{ IL-1RN genotype } \\
\hline & & & & \multicolumn{3}{|l|}{$U C$} & \multicolumn{3}{|c|}{ Controls } & \multirow[b]{2}{*}{ Power * } \\
\hline & & & & 1,1 & 1,2 & 2,2 & 1,1 & 1,2 & 2,2 & \\
\hline Mansfield $^{23}$ & $2.03(1.30-3.18)$ & 113 & 261 & 46 & 55 & 12 & 152 & 92 & 17 & 0.58 \\
\hline Louis $^{26}$ & $1.38(0.78-2.45)$ & 113 & 89 & 65 & 41 & 7 & 58 & 25 & 6 & 0.57 \\
\hline Bioque $^{27}$ & $1.35(0.73-2.49)$ & 111 & 86 & 59 & 44 & 8 & 52 & 27 & 7 & 0.57 \\
\hline Hacker $^{28}$ & $0.66(0.37-1.20)$ & 57 & 234 & 35 & 20 & 2 & 120 & 101 & 13 & 0.34 \\
\hline Heresebach $^{29}$ & $0.54(0.30-0.96)$ & 87 & 108 & 55 & 25 & 7 & 52 & 46 & 10 & 0.47 \\
\hline Andus $^{30}$ & $1.70(0.78-3.71)$ & 54 & 50 & 21 & 29 & 4 & 26 & 22 & 2 & 0.33 \\
\hline Stokkers ${ }^{31}$ & $1.10(0.62-1.97)$ & 55 & 270 & 27 & 26 & 2 & 139 & 105 & 26 & 0.33 \\
\hline Present study & $1.31(1.01-1.69)$ & 320 & 827 & 155 & 139 & 26 & 456 & 317 & 54 & 0.94 \\
\hline
\end{tabular}

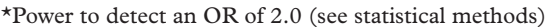

HC, healthy controls. 
major susceptibility genes. Linkage analysis may be too insensitive to detect small effect genes. Association studies using either case control designs or a family based association test, such as the transmission/disequilibrium test ${ }^{40}$ can have greater power to detect genes of modest effect. ${ }^{41}$ We have performed a well powered case control study, and in addition reviewed other studies which have performed case control analyses to test an association between IL1-RN and UC. At the current time, we are not aware of any family based association studies that have been performed. Family based association analyses are robust to population admixture, and therefore we feel that a well powered study of this type should now be pursued for further confirmation of our current findings.

The discrepancy between the results of both this and the previous Sheffield study, ${ }^{23}$ and those of other white Northern European Caucasian series needs explanation. It is unlikely that methodological differences can explain the inconsistencies between studies. Six of the seven previous investigators ${ }^{23} 26-30$ used the same primers and protocols. Although in this study we have used the exon 2 IL-1RN $(+2018)$ polymorphism as a marker for the VNTR polymorphism, we have demonstrated by parallel genotyping of over 269 individuals that the rarer allele $2(\mathrm{C})$ of this single nucleotide polymorphism is completely associated with the VNTR allele 2. A single study from Holland ${ }^{31}$ used the intron $2(+2073)$ polymorphism but the same group had previously demonstrated that the rarer allele is also completely associated with the VNTR allele $2 .^{22}$

Ethnic differences are also unlikely to explain the discrepancies in the results of these studies as they were all performed in white Northern European Caucasians. However, there was variability in allele 2 carriage rates in the control populations, varying from $35 \%$ to $52 \%$, which may explain some of the inconsistencies between studies. This is likely to reflect the limited number of controls used in several of the series. In association studies it is optimum to have twice as many controls as cases and this criterion was fulfilled in our present investigation which had the largest number of controls.

Variation in diagnostic criteria and methods of patient assessment may be relevant. In view of similarities between UC and CD and in the absence of sensitive and specific serological tests for distinguishing these related conditions, most authorities accept that colonoscopy with colonic biopsies is the most accurate and reliable method of confirming disease diagnosis. ${ }^{42}$ Even with such investigations it can still be impossible to distinguish between UC and CD in approximately $20 \%$ of cases. This present study uniformly used colonoscopic assessment with histology of a colonic series of biopsies to confirm the disease diagnosis and excluded patients where this was uncertain, such as those with indeterminate colitis. It is unclear if the previous studies used such rigorous inclusion criteria.
Different sets of genes may result in similar disease expression in different individuals and UC may in fact represent a number of distinct but closely related disorders that share some but not all genetic factors. This may explain the variable disease behaviour seen in clinical practice. The concept of genetic and phenotypic heterogeneity within UC, and indeed IBD as a whole, is an area of considerable interest. ${ }^{43}$ Such genetic heterogeneity has been suggested as an explanation for the differences in the results of these studies. ${ }^{26}$ Perhaps allele 2 of the IL-1RN is associated exclusively with a particular phenotype of UC. Disease extent, need for surgery, and familial disease are the most widely discussed phenotypes in IBD. Comparison of the studies with respect to extent of disease show similar proportions of individuals with distal, left sided, and extensive disease, and these proportions accord well with previous published series of disease extent in UC. ${ }^{44}$ Due to the absence of data it is not possible to compare the studies with respect to surgery or familial disease. It is difficult however to explain why the proportions of the putative different phenotypes, even if as yet undefined, should be significantly different between two centres in the same country. Furthermore, this current study represents results from over $30 \%$ of patients attending a single centre with UC which argues against case selection.

The most plausible explanation for the differences in the results of these similar studies may lie in the sample sizes and hence lack of power. The previous seven studies had at least 54 and at most 113 patients, which gives a power to detect an OR of 2.0 of $33 \%$ and $58 \%$, respectively, whereas the current study of 320 patients has a power of $94 \%$ (see table 4 ). We suggest that the previous non-confirmatory studies may simply represent false negatives due to lack of power to detect a small increase in allele frequency in patients. Indeed, three of these six studies showed a non-significant trend towards association with ORs which were higher than our current study. ${ }^{26} 2730$

To verify this hypothesis a meta-analysis of all studies in Northern European Caucasian populations was performed and this confirmed an overall association. This also provided evidence of heterogeneity between the studies suggesting that the association may not be present in all disease groups even within such a well defined population and that therefore there may exist more than one disease pathway. However, it appears that one study ${ }^{29}$ is responsible for most of the heterogeneity observed. Indeed, close analysis of the UC patients included in this study show that none had been treated with azathioprine, suggesting selection of cases, which may explain the heterogeneity observed. For interest, we then performed the meta-analysis omitting this study ${ }^{29}$ in an attempt to increase homogeneity. This gave an OR of 1.3 (95\% CI $1.1-1.6 ; p=0.001 ; \chi^{2}=10.2$, $1 \mathrm{df})$. Woolf's test for heterogeneity is then no longer significant $\left(\chi^{2}=9.6 ; 6 \mathrm{df} ; \mathrm{p}=0.14\right)$ suggesting that the discrepancies are not that great. Although all meta-analyses suffer from 
publication bias, we have included both published studies and those presented in abstract form in this meta-analysis to limit this effect. Moreover, studies that have not been presented will not necessarily be unfavourable and several non-significant results with the correct directional trend could potentially increase the overall significance.

This association study also demonstrates that the allele is most highly associated with patients who have extensive disease suggesting that the polymorphism is a marker of disease extent. This concurs with the original subgroup analysis in the Sheffield study ${ }^{23}$ and that of a Dutch study, ${ }^{27}$ and also recent data from Oxford. ${ }^{34}$ Classifying UC by extent of disease can however be difficult as this has been variously defined by radiological, endoscopic, and histological criteria in different studies. Furthermore, it has been suggested that the extent of colonic involvement in UC is dynamic and not static and may extend or regress during the course of the disease. ${ }^{45}$

The requirement for colectomy in UC is a further phenotypic classification that has clinical relevance in terms of disease severity. In this study there was an increased carriage rate of the allele 2 in the subgroup of patients undergoing surgery although the small number of patients makes it difficult to draw definitive conclusions. Previous data have been contradictory with subgroup analysis of the French study $^{29}$ demonstrating an association with carriage of the allele 2 while data from Oxford ${ }^{34}$ failed to confirm this.

Recent observations have suggested that allele 2 of the IL-1RN gene is associated with reduced levels of IL-1ra in the colonic mucosa of patients with $\mathrm{IBD}^{46}$ (and unpublished data). This may prevent adequate control of mucosal inflammation and provides a biologically plausible explanation for the genetic association between the allele and the disease. However, the VNTR polymorphism is in a non-coding region of the gene in intron 2 and the exon 2 polymorphism is a conservative base pair change which does not alter the protein amino acid sequence. It is difficult to envisage how either polymorphism has a direct functional effect in terms of IL-1 ra production and indeed unpublished gene reporter studies showed that the VNTR itself had no effect on gene transcription (personal communication). It is therefore likely that both polymorphisms are in linkage disequilibrium with a functional polymorphism, as yet undefined. This functional genetic change is perhaps most likely to be either in the gene promoter region or in the $3^{\prime}$ untranslated region, affecting gene transcription or post-transcriptional events, respectively. Alternatively, although less likely, is the possibility that the demonstrated association is due to linkage disequilibrium with a genetic variant in another gene (perhaps yet to be characterised) within the gene cluster, due to the presence of linkage disequilibrium. ${ }^{47}$ Indeed, four novel genes have recently been identified within the IL-1 gene cluster. ${ }^{48}$

In summary, this is the largest association study to date in well defined patients with UC, assessing the putative genetic association with allele 2 of the IL-1RN. The association with disease was confirmed and this conclusion is supported by a meta-analysis of this and previous studies in North European Caucasians. In addition, the allele 2 may also be a determinant of disease severity in terms of extent of disease and the need for surgery.

This research was funded by the National Association of Colitis and Crohn's Disease and the Special Trustees of the Former United Central Sheffield Hospitals. Dr M J Carter is a Digestive Disorders Foundation Research Training Fellow.

Conflict of interest. F S di Giovine and G W Duff are co-holders of patents on IL-1 genes as susceptibility markers for inflammatory diseases.

1 Tysk C, Lindberg E, Jarnerot G, et al. Ulcerative colitis and Crohn's disease in an unselected population of monozygotic and dizygotic twins. A study of heritability and the influence of smoking. Gut 1988;29:990-6.

2 Orholm M, Munkholm P, Langholz E, et al. Familial occurrence of inflammatory bowel disease. $N \mathrm{Engl} F \mathrm{Med}$ 1991;324:84-8

3 Orholm M, Iselius L, Sorensen T, et al. Investigation of inheritance of chronic inflammatory bowel diseases by complex segregational analysis. BMF 1993;306:20-4.

4 Satsangi J, Jewell DP. The genetics of inflammatory bowel disease. Gut 1997;40:572-4.

5 Satsangi J, Parkes M, Louis E, et al. Two stage genome-wide search in inflammatory bowel disease provides evidence for susceptibility loci on chromosomes 3, 7 and 12. Nat Genet 1996;14:199-202.

6 Hugot J-P, Laurent-Puig P, Gower-Rousseau C, et al. Mapping of a susceptibility locus for Crohn's disease on chromosome 16. Nature 1996;379:821-3.

7 Sartor RB. Cytokines in intestinal inflammation: Pathophysiological and clinical considerations. Gastroenterology 1994;106:533-9.

8 Dinarello CA, Wolff SM. The role of interleukin-1 in disease. N Engl F Med 1993;328:106-13.

9 Arend WP. Interleukin-1 receptor antagonist. Adv Immunol 1993;54:167-227.

10 Nicklin M, Weith A, Duff GW. A physical map of the region encompassing the human interleukin-1 alpha, interleukin-1 beta and interleukin-1 receptor antagonist genes. Genomics 1994;19:382-4.

11 Cominelli F, Nast CC, Clark BD, et al. Interleukin-1 (IL-1) gene expression, synthesis and effect of specific IL-1 receptor blockade in rabbit immune complex colitis. F Clin Invest 1990;86:972-80.

12 McCall RD, Haskill S, Zimmerman EM, et al. Tissue interleukin-1 and interleukin-1 receptor antagonist expression in enterocolitis in resistant and susceptible rats. Gastroenterology 1994;106:960-72.

13 Ligumsky M, Simon PL, Karmeli F, et al. Role of interleukin-1 in inflammatory bowel disease - enhanced production during active disease. Gut 1990;31:686-9.

14 Mahida YR, Wu K, Jewell DP. Enhanced production of interleukin-1 beta by mononuclear cells isolated from the mucosa with active ulcerative colitis or Crohn's disease. Gut 1989;30:835-8.

15 Casini-Raggi V, Kam L, Chong YJT, et al. Mucosal imbalance of IL-1 and IL-1 receptor antagonist in inflammatory bowel disease: a novel mechanism of chronic intestinal inflammation. F Immunol 1995;154:2434-40.

16 Nishiyama T, Mitsuyama K, Toyonaga A, et al. Colonic mucosal interleukin-1 receptor antagonist in inflammatory bowel disease. Digestion 1994;55:368-73.

17 Cominelli F, Nast CC, Duchini A, et al. Recombinant interleukin-1 receptor antagonist blocks the proinflammatory activity of endogenous interleukin- 1 in rabbit immune colitis. Gastroenterology 1992;103:65-71.

18 Hirsch E, Irikura VM, Paul SM, et al. Functions of interleukin-1 receptor antagonist in gene knockout and overproducing mice. Proc Natl Acad Sci USA 1996;93: $11008-13$.

19 Ferretti M, Casini-Raggi V, Pizarro TT, et al. Neutralisation of endogenous IL-1 receptor antagonist exacerbates and prolongs inflammation in rabbit immune colitis. $\mathcal{F}$ Clin Invest 1994;94:449-53.

20 Tarlow JK, Blakemore AIF, Lennard A, et al. Polymorphism in human IL-1 receptor antagonist gene intron 2 is caused by variable numbers of an $86-\mathrm{bp}$ tandem repeat. Hum Genet 1993;91:403-4.

21 Clay FE, Tarlow JK, Cork MJ, et al. Novel interleukin-1 receptor antagonist exon polymorphisms and their use in allele-specific mRNA assessment. Hum Genet 1996;97: $723-6$.

22 Guasch JF, Bertina RM, Reitsma PH. Five novel intragenic dimorphisms in the human interleukin-1 genes combine to high informity. Cytokine 1996;8:598-602.

23 Mansfield JC, Holden H, Tarlow JK, et al. Novel genetic association between ulcerative colitis and the antiinflammatory cytokine interleukin-1 receptor antagonist. Gastroenterology 1994;106:637-42. 
24 Tountas NA, Casini-Raggi V, Yang H, et al. Functional and ethnic association of allele 2 of IL-1 receptor antagonist gene in ulcerative colitis. Gastroenterology 1999;117:806

Duerr RH, Tran T. Association between ulcerative colitis and a polymorphism in intron 2 of the interleukin-1 receptor antagonist gene. Gastroenterology 1995;108:A812.

26 Louis E, Satsangi J, Roussomoustakaki M, et al. Cytokine gene polymorphisms in inflammatory bowel disease. Gut 1996;39:705-10.

27 Bioque G, Bouma G, Crusius JBA, et al. Evidence for genetic heterogeneity in IBD: The interleukin-1 receptor antagonist in the predisposition to suffer from ulcerative colitis. Eur 7 Gastroenterol Hepatol 1996;8:10510.

28 Hacker UT, Gomolka M, Keller E, et al. Lack of association between an interleukin-1 receptor antagonist gene polymorphism and ulcerative colitis. Gut 1997;40:623-7.

29 Heresbach D, Alizadeh M, Dabadie A, et al. Significance of interleukin-1 beta and interleukin-1 receptor antagonist interleukin-1 beta and interleukin-1 receptor antagonist genetic polymorphism in inflam

30 Andus T, Caesar I, Vogi D, et al. Association of HLA-DR15, P-ANCA and IL-1 receptor antagonist allele 2 with ulceraP-ANCA and IL-1 receptor antagonist allele

31 Stokkers PCF, van Aken BE, Basoski N, et al. Five genetic markers in the interleukin 1 family in relation to inflammatory bowel disease. Gut 1998;43:33-9.

32 Jenkins D, Balsitis M, Gallivan S, et al. Guidelines for the initial biopsy diagnosis of suspected chronic idiopathic inflammatory bowel disease. The British Society of Gastroenterology initiative. Gut 1997;50:93-105.

33 Miller SA, Dykes DD, Polesky HF. A simple salting out procedure for extracting DNA from human nucleated cells. Nucleic Acids Res 1988;16:1215.

34 Roussomoustakaki M, Satsangi J, Welsh K, et al. Genetic markers may predict disease behaviour in patients with ulcerative colitis. Gastroenterology 1997;112:1845-53.

35 Brett PM, Yasuda N, Yiannakou JY, et al. Genetic and immunological markers in pouchitis. Eur $\mathcal{f}$ Gastroenterol Hepatol 1996;8:951-5.
36 Sasieni PD. From genotypes to genes: doubling the sample size. Biometrics 1997;53:1253-61.

37 Mantel N, Haenszel W. Statistical aspects of the analysis of data from retrospective studies of disease. $\mathcal{F}$ Natl Cancer Inst 1959;22:719-48.

38 Mantel N, Fleiss JL. Minimum expected cell size requirements for the Mantel-Haenszel one-degree-of-freedom chi-square test and a related rapid procedure. Am f Epidemiol 1980;112:129-34.

39 Woolf B. On estimating the relation between blood group and disease. Ann Hum Genet 1955;19:25153.

40 Spielman RS, Ewens WJ. The TDT and other family-based tests for linkage disequilibrium and association. Am f Hum Genet 1996;59:983-9.

41 Risch N, Merikangas K. The future of genetic studiesof complex human diseases. Science 1996;273:1516-17.

42 Podolsky DK. Medical progress: inflammatory bowel disease (part 2). N Engl F Med 1991;325:1008-16.

43 Cho JH, Brant SR. Genetics and genetic markers in inflammatory bowel disease. Curr Opin Gastroenterol 1998;14: 283-8.

44 Farmer RG, Easley KA, Rankin GB. Clinical patterns, natural history, and progression of ulcerative colitis: A long-term follow-up of 1116 patients. Dig Dis Sci 1993;38:1137-46.

45 Niv Y, Bat L, Ron E, et al. Change in extent of colonic involvement in ulcerative colitis: A colonoscopic study. Am 7 Gastroenterol 1987;82:1046-51.

46 Andus T, Daig R, Vogl D, et al. Imbalance of the interleukin-1 system in colonic mucosa-association with intestinal inflammation and interleukin-1 receptor antagonist genotype 2. Gut 1997;41:651-7.

47 Cox A, Camp NJ, Nicklin MJH, et al. An analysis of linkage disequilibrium in the interleukin-1 gene cluster using a novel grouping method for multi-allelic markers. Am $\mathcal{F}$ Hum Genet 1998;62:1180-8.

48 Smith DE, Renshaw BR, Ketchem RR, et al. Four new members expand the interleukin-1 superfamily. $f$ Biol Chem 2000;275:1169-75. 